\title{
VIDEO
}

\section{Overtube-assisted EUS with FNA for esophageal stenosis}
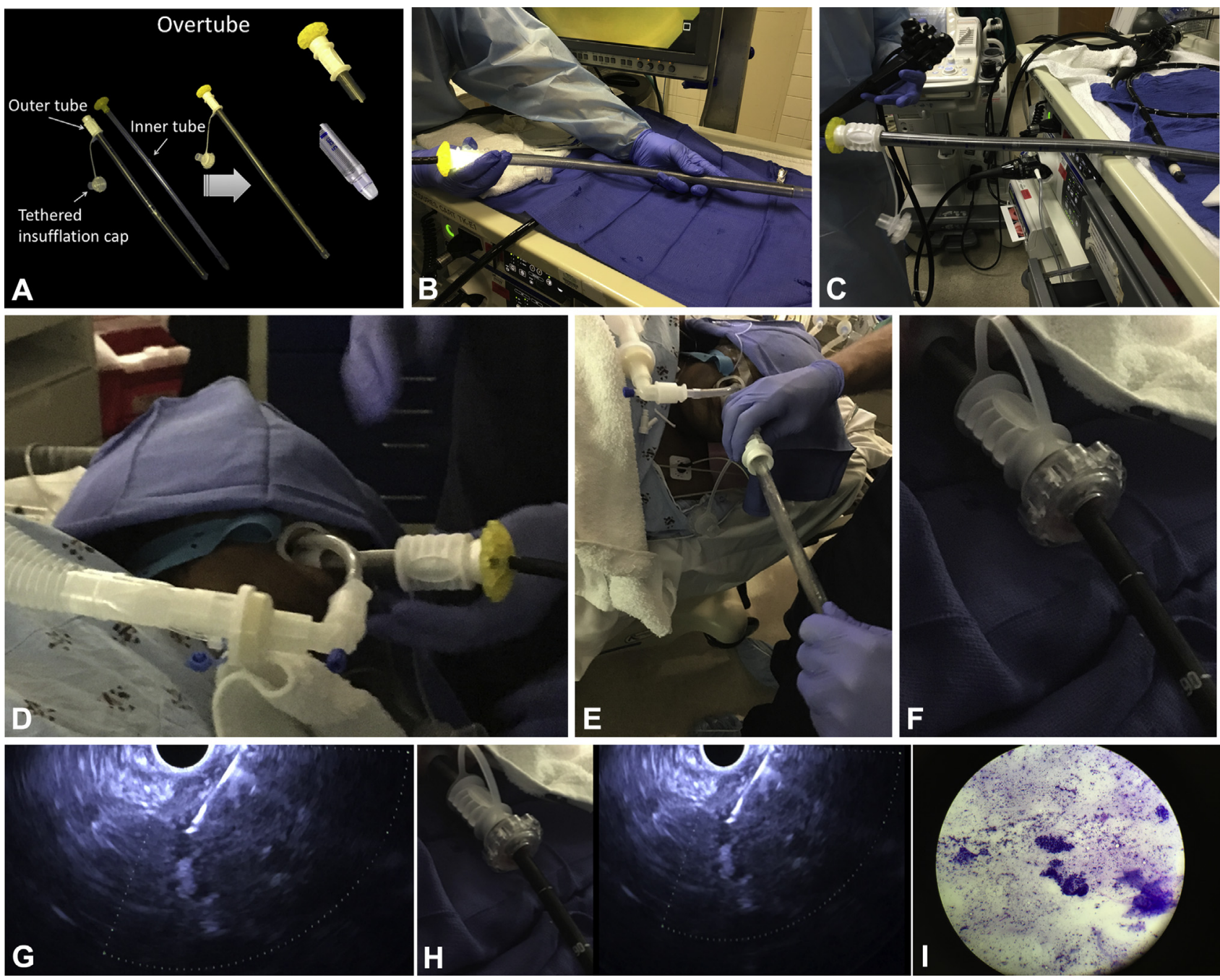

Figure 1. A, Overtube's parts. B, Overtube-assisted EUS with FNA. C, The overtube is assembled onto the endoscope. D, EUS echoendoscope is introduced through the tethered insufflation cap. $\mathbf{E}$, The endoscope is advanced through the stenosis. $\mathbf{F}$, $\mathbf{G}$, Inner overtube is removed. $\mathbf{H}$, Normal FNA is performed with the endoscope. I, Rapid on-site evaluation.

An 82-year-old woman presented to the hospital because of 3 weeks of abdominal pain, weight loss, and early satiety. CT imaging demonstrated a $3-\mathrm{cm}$ pancreatic body mass.

The patient was scheduled for EUS with general anesthesia. As practice for the endoscopist, an EGD was performed before the EUS (Video 1, available online at www.VideoGIE.org). This revealed a challenging esophageal intubation at the oropharynx, secondary to the body shape without any pathologic condition; however, this was an obese patient with a short neck with challenging intubation, even with the standard flexible EGD endoscope $(9 \mathrm{~mm})$. Her weight was $79.38 \mathrm{~kg}(173.8 \mathrm{lb})$, and her height was $162 \mathrm{~cm}$ (63.78 in) with a body mass index of 30. The esophageal intubation required mild forward pressure and deflation of the tracheal cuff to enable passage of the adult endoscope. Passage of the EUS endoscope into the stomach proved impossible. The echoendoscope was removed, and a gastric overtube 
(Fig. 1A and B) was placed into the oropharynx and through the esophagus under direct visualization with the adult endoscope.

After appropriate positioning of the overtube (Fig. 1C-E), the EUS was successfully placed within the lumen of the overtube (Fig. 1F), enabling EUS identification of a hypoechoic $28 \times 24 \mathrm{~mm}$ pancreatic tail mass, and FNA with a $25 \mathrm{G}$ needle was performed (Fig. $1 \mathrm{G}$ and $\mathrm{H}$ ). On-site cytopathologic examination was available, and a specimen from the first pass was positive for adenocarcinoma (Fig. 1I).

This demonstrates the successful use of an overtube to assist safe passage of larger, difficult-to-manipulate endoscopes without forward view through esophageal stenosis to obtain a diagnosis and to reduce the need for repeated procedures.

\section{DISCLOSURE}

All authors disclosed no financial relationships relevant to this publication.

Alvaro Martínez-Alcalá, MD, Krupali Thakar, MD, Joel Augustus, MD, Klaus Mönkemüller, MD, PhD, FASGE, Ali M. Ahmed, MD, Basil I. Hirschowitz Endoscopic Center of Excellence, Division of Gastroenterology and Hepatology, University of Alabama at Birmingham, Birmingham, Alabama, USA

Copyright (c) 2017 American Society for Gastrointestinal Endoscopy. Published by Elsevier Inc. This is an open access article under the CC BY-NC-ND license (http://creativecommons.org/licenses/by-nc-nd/4.0/).

http://dx.doi.org/10.1016/j.vgie.2017.02.010 